Journal of Extension Education

Vol. 28 No. 1, 2016

\title{
Soil Health Card Adoption Behaviour among Beneficiaries of Bhoochetana Project in Andhra Pradesh
}

\author{
K. Raghavendra Chowdary ${ }^{1}$ and Ravi Kumar Theodore ${ }^{2}$
}

\begin{abstract}
A research study was carried out in order to evaluate the performance of the Bhoochetana Project of Government of Andhra Pradesh initiated in the year 2010-11 for distributing Soil Health Cards (SHCs) to farmers. Almost all the respondents were seen to be distributed between medium and high level categories in respect of value attribution to $\mathrm{SHC}$ recommendations. With respect to comparative value attribution, third rank was assigned to SHC recommendations. More than two-thirds (67.00\%) of the respondents had high level of satisfaction on SHC recommendations. Out of the 100 respondents studied, 47 of them had followed SHC recommendations all the five years. Among adopters of SHC recommendations, $100 \%$ per cent of the farmers had adopted the SHC recommendations as such, without any deviation. Whereas, among non-Adopters of SHC recommendations, an overwhelming proportion (92.45\%) of farmers fell under excess adoption category. Inadequate follow-up by extension agency was the foremost constraint expressed by majority of the respondents.
\end{abstract}

Keywords : Soil Health Card, Adoption Behaviour, Andhra Pradesh

\section{INTRODUCTION}

Soil health plays a vital role to ensure sustainable agricultural production. However, deteriorating soil health has been a cause of concern, which has led to sub-optimal utilization of farm resources. According to Yadav, et al., 2006,"knowledge level and adoption of Soil Fertility Management (SFM) practices are relatively less i.e. 65\% of them have no knowledge about SFM practices and just eight per cent of them have adopted SFM practices". Judicious application of chemical fertilizers by farmers in crops is very much essential to achieve maximum production and to earn maximum profit. Srivastava and Pandey (1999) have reported that "Research studies reveal that most of the farmers are using continuously larger quantities of chemical fertilizers to increase production without knowing the fertility status of the soils of their fields". Soil testing helps farmers in judicious application of chemical fertilizers to the crops. The soil testing of a particular field gives reliable information about

1 - Ph.D. Scholar, Dept. of Agri. Extn, S.V. Agri College, Tirupathi, Andhra Pradesh

2 - Professor, TRRI, Aduthurai, Thanjavur

Received : 26-5-2016; Accepted : 13-6-2016 
the deficiency of nutrients in the soil as well as hazards such as soil acidity, alkalinity, salinity, etc. After testing the soil, farmers can know the exact amount of nutrients to be applied for a particular crop.

However, in the past two decades, the fertility status of soils has decreased drastically due to indiscriminate use of fertilizers i.e. the Soil Nutrient Response Ratio has decreased from 14.06 in 199091 to 8.59 in 2010-11 (Mission Project to Boost Productivity in Rainfed Areas of Andhra Pradesh - 2011). Therefore, the Government of Andhra Pradesh initiated the Bhoochetana Project in the year 2010-11 for distributing Soil Health Cards (SHCs) to farmers in order to encourage judicious application of fertilizers, to increase productivity of crops, and to maintain soil fertility. The project is going for the last six years since its inception. Soil samples are collected @ 10 samples per village from the farmers under this project, which are tested in the Soil Testing Labs, based on which SHCs are distributed to the farmers.In the light of the above a study was conducted to evaluate the project with the following specific objectives:

1. To analyze the adoption pattern of beneficiary farmers with respect to SHC recommendations.

2. To identify the constraints faced by beneficiary farmers in adoption of SHC recommendations.
3. To elicit suggestions to increase adoption level of SHC recommendations by farmers.

\section{METHODOLOGY}

The study was conducted in Kurnool District of Andhra Pradesh. Kurnool district consists of 54 Mandals (Blocks) and among them, Orvakal and Banaganapalli Blocks were selected based on maximum number of SHC holders. Among the 20 villages of Orvakal Block, 10 villages were selected for the study, and among 39 villages of Banaganapalli Block, 10 villages were selected for the study, based on simple random sampling. Based on proportionate random sampling method, 100 respondents were selected from the 20 villages who formed the sample of the study.

The variables included in the study were: (i) Value attribution to SHC recommendations, (ii) Comparative Value Attribution, (iii) Satisfaction Index, and (iv.) Pattern of adoption of SHC recommendations. Value attribution to SHC recommendations was operationalized as the degree to which a farmer respondent placed worth on the SHC recommendations. The respondents were asked to indicate their value attribution on a scale of 1 to 10 , with one score indicating low value attribution and a score of 10 meaning high value attribution. Based on the minimum and maximum scores, the respondents were classified into low, 
medium, and high using frequency distribution. Comparative Value Attribution was operationalized as the relative importance given to SHC based recommendations by a farmer respondent in comparison to other farm technologies or farm operations recommended. The respondents were asked to rank the technologies / operations from 1 to 10 , based on the comparative importance as perceived by them. The ranks were analyzed using Garett ranking method. Satisfaction Index referred to the degree to which a respondent was satisfied with the SHC recommendations. The Index consisted of five statements developed for the study. The respondents were asked to rate each statement on a five point continuum viz., Not Satisfied, Less Satisfied, Satisfied, Very Satisfied and Fully Satisfied, with scores of 1 , 2, 3, 4 and 5 respectively. Based on the minimum and maximum scores, the respondents were classified into low, medium and high categories using frequency distribution method.

Pattern of adoption of SHC recommendations was assessed in terms of 'Period of Adoption', 'Years of Adoption' and 'Extent of Adoption'.Period of Adoption referred to the time period of adoption of the SHC recommendations by a farmer respondent between the year 2010-11 (Year of implementation of Bhoochetana project) and 2014-15 (Study period). Frequency distribution method was followed in order to categorize the respondents based on their time period of adoption.Years of Adoption referred to the actual years of adoption of SHC recommendations by a respondent, which is a derivative of 'period of adoption'. The respondents were classified into different categories based on frequency distribution method.Extent of adoption of SHC recommendations was operationalized as the degree to which a respondent actually adopted the SHC based recommendations. The Extent of Adoption variable was measured by means of the Adoption Index followed by Theodore (1988), which is given as follows:

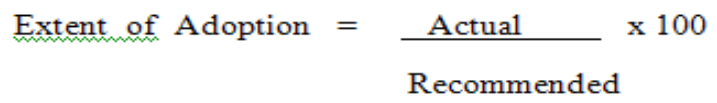

The extent of adoption was worked out for each of the SHC recommendations, as indicated in the SHC of each farmer respondent viz., (i) Nutrients / Fertilizers - Urea (N),SSP (P) / DAP, MOP (K), Organic manure, and (ii) Problematic soils -Alkali - Gypsum (t/ha), Acidic $\mathrm{CaCo}_{3}(\mathrm{~kg} / \mathrm{ac})$. The recommendation-wise adoption values for a respondent were summed up and then divided by the number of recommendations, and finally the resulting value was multiplied by 100 to arrive at the Extent of Adoption score in terms of percentage. Lower percentage indicated 'less adoption' and higher percentage meant 'higher adoption'. Based on the percentages, the respondents were classified into low, medium and high categories using frequency distribution method. 


\section{FINDINGS AND DISCUSSION}

\section{Value Attribution to Soil Health Card (SHC) Recommendations}

The classification of respondents based on their value attribution to SHC recommendations and the corresponding frequency distribution is presented in Table 1.

From Table 1 it is inferred that majority $(60.0 \%)$ of the respondents had medium level of value attribution to SHC had low level of value attribution to SHC recommendations.

Almost all the respondents are seen to be distributed between medium and high categories in respect of value attribution. This may be as a result of the efforts taken under Bhoochetana project to popularize the importance of SFM.

\section{Comparative Value Attribution}

The results of the analysis of

Table 1. Distribution of Respondents According to Value Attribution to SHC Recommendations $(n=100)$

\begin{tabular}{|c|c|c|}
\hline S1.No. & Value Attribution Categories & Per cent \\
\hline 1. & Low (1-3 scores) & 5.00 \\
\hline 2. & Medium (4-6 scores) & 60.00 \\
\hline \multirow[t]{3}{*}{3.} & High (7-10 scores) & 35.00 \\
\hline & Total & 100.00 \\
\hline & Mean & 5.9 \\
\hline
\end{tabular}
of value attribution, and the rest (5.0\%)

Table 2. Distribution of Respondents According to Comparative Value ttribution

$(n=100)$

\begin{tabular}{|c|l|c|c|}
\hline S1.No. & \multicolumn{1}{|c|}{ Technologies / Operations } & $\begin{array}{c}\text { Garrett's Mean } \\
\text { Score }\end{array}$ & Ranks \\
\hline 1. & Water management & 66.65 & $\mathrm{I}$ \\
\hline 2. & HYV / Hybrids & 66.35 & $\mathrm{II}$ \\
\hline 3. & SHC recommendations & 65.44 & $\mathrm{III}$ \\
\hline 4. & Crop protection (Pests) & 64.65 & $\mathrm{IV}$ \\
\hline 5. & Weed Management & 52.75 & $\mathrm{~V}$ \\
\hline 6. & Land preparation & 49.67 & VI \\
\hline 7. & Market intelligence & 41.25 & VII \\
\hline 8. & Integrated Farming System (IFS) & 35.50 & VIII \\
\hline 9. & $\begin{array}{l}\text { Post harvest technology -Processing and } \\
\text { value addition }\end{array}$ & 30.35 & $\mathrm{IX}$ \\
\hline 10. & Farm mechanization & 28.75 & $\mathrm{X}$ \\
\hline
\end{tabular}


FromTable 2, itisinferred that water management was ranked first among all the 10 technologies / operations, followed by second rank to HYV / hybrids, third rank for SHC recommendations, fourth rank for crop protection (Pests), fifth rank for weed management, sixth rank for land preparation, seventh rank for market intelligence, eighth rank for IFS, ninth rank for post harvest technology - processing and value addition, and finally the tenth rank was assigned to farm mechanization.

Water management was ranked first by the respondents, which may be due to the reason that the area under rainfed agriculture in Kurnool district is about $6,85,000$ ha (net irrigated area is around 1,75,000 ha), and therefore water management would have assumed greater importance.
HYV / hybrids was ranked second by the farmers. The quality of seed decides the performance of the crop contributing for nearly 20 per cent of yield increase, which may be the reason for this finding. SHC recommendations was ranked third in the order. This finding may have occurred as a result of the efforts taken under the Bhoochetana project.

\section{Satisfaction Index}

The distribution of respondents based on satisfaction index is furnished in Table 3.

Table 3 shows that more than two-thirds $(67.00 \%)$ of the respondents had high level of satisfaction on $\mathrm{SHC}$ recommendations, and the rest (33.00\%) had medium level of satisfaction on SHC recommendations.

Table 3. Distribution of Respondents According to Satisfaction Index

\begin{tabular}{|c|c|c|}
\hline $\begin{array}{c}\text { S1. } \\
\text { No. }\end{array}$ & Satisfaction Index categories & Per cent $(n=100)$ \\
\hline 1. & Low (5-11 scores) & -- \\
\hline 2. & Moderate (12-1scores) & 33.00 \\
\hline 3. & High (19-25 scores) & 67.00 \\
\hline & Total & 100.00 \\
\hline & Mean & 23.17 \\
\hline
\end{tabular}

It is seen that all the respondents were distributed between high and moderate categories with respect to satisfaction index. This finding may be as a result of the initiatives taken by the extension functionaries under the Bhoochetana project.
Pattern of Adoption of Soil Health Card (SHC) recommendations

The results of the analysis of pattern of adoption of SHC recommendations assessed in terms of 'Period of Adoption', 'Years of Adoption' 
Soil Health Card Adoption Behaviour among Beneficiaries of Bhoochetana Project in Andhra Pradesh

and 'Extent of Adoption' are presented in Tables 4, 5 and 6.

\section{Period of Adoption}

The results of the analysis with respect to period of adoption of SHC recommendations are presented in Table 4.
Table 4 shows that out of the 100 respondents studied, 47 of them had followed SHC recommendations all the five years. The remaining respondents (53) had followed the SHC recommendations for less than five years.

Table 4. Distribution of Respondents According to Period of Adoption of SHC Recommendations

\begin{tabular}{|c|l|c|}
\hline S1. No. & \multicolumn{1}{|c|}{ Adoption Period } & $\begin{array}{c}\text { No. of Adopters } \\
\text { (n=100) }\end{array}$ \\
\hline 1. & $2010-11$ to 2014-15 & 47 \\
\hline 2. & $2010-11$ to 2013-14 & 9 \\
\hline 2. & $2010-11$ to 2012-13 & 9 \\
\hline 3. & $2010-11$ to 2011-12 & 6 \\
\hline 4. & $2011-12$ to 2013-14 & 8 \\
\hline 5. & $2011-12$ to 2012-13 & 3 \\
\hline 6. & $2012-13$ & 4 \\
\hline 7. & $2013-14$ & 2 \\
\hline 8. & $2014-15$ & \\
\hline
\end{tabular}

\section{Years of Adoption}

The results of analysis of years of

Table 5. Distribution of Respondents According to years of Adoption of SHC Recommendations

$(\mathrm{n}=100)$

\begin{tabular}{|c|c|c|}
\hline S1.No. & Years of Adoption & No. of Adopters \\
\hline 1. & 5 Years & 47 \\
\hline 2. & 4 Years & 9 \\
\hline 3. & 3 Years & 21 \\
\hline 4. & 2 Years & 14 \\
\hline 5. & 1 Year & 9 \\
\hline & Total & $\mathbf{1 0 0}$ \\
\hline
\end{tabular}


Table 5 indicates that out of the total five years of adoption period (which is the maximum period), 47 respondents had followed the SHC recommendations for all the five years. This is followed by nine respondents who had followed for four years, 21 respondents for three years, 14 respondents for two years, and the rest nine respondents for one year.

Nearly half of the respondents were observed to have adopted the SHC recommendations for the maximum period of 5 years, which may be as a result of the efforts taken under the Bhoochetana project. Discontinued adopters were to the tune of 53 per cent, who had followed the SHC recommendations for less number of years i.e., 4 and less. This finding may be as a result of following reasons viz., inadequate follow-up by extension agency, no visible result, complex to adopt the recommendations, and less knowledge as expressed by a considerable proportion of the respondents as constraints faced in adoption of SHC recommendations.

\section{Extent of Adoption}

The results of the analysis of extent of adoption of SHC recommendations are presented in Table 6.

From Table 6, it is seen that among adopters of SHC recommendations, 100\% per cent of the farmers had adopted the SHC recommendations as such without any deviation. Whereas, among nonadopters of SHC recommendations, an overwhelming proportion (92.45\%) of farmers fell under excess adoption category, and the rest (7.55\%) belonged to less adoption category.

Table 6. Distribution of Respondents According to Extent of Adoption of SHC Recommendations

\begin{tabular}{|c|c|c|c|c|c|}
\hline \multirow[t]{2}{*}{ S1.No. } & \multirow[t]{2}{*}{$\begin{array}{c}\text { Extent of Adoption } \\
\text { Categories }\end{array}$} & \multicolumn{2}{|c|}{$\begin{array}{l}\text { Adopters of SHC } \\
\text { Recommendations } \\
\qquad(\mathrm{n}=47)\end{array}$} & \multicolumn{2}{|c|}{$\begin{array}{l}\text { Non-Adopters of SHC } \\
\text { Recommendations } \\
\qquad(\mathrm{n}=53)\end{array}$} \\
\hline & & No. & Per cent & No. & Per cent \\
\hline 1. & Less adoption (-) & -- & -- & 4 & 7.55 \\
\hline 2. & $\begin{array}{l}\text { Recommended Level of } \\
\text { Adoption }\end{array}$ & 47 & 100.00 & -- & -- \\
\hline 3. & Excess adoption $(+)$ & -- & -- & 49 & 92.45 \\
\hline & Total & 47 & 100.00 & 53 & 100.00 \\
\hline
\end{tabular}

It was found that among the 100 respondents surveyed, 47 farmers had adopted the SHC recommendations in toto, whereby they were classified as Adopters. This may be due to the reason of medium to high level of value attribution, high level of comparative value attribution, and high level of satisfaction on SHC recommendations observed among the respondents. 
It was observed that majority of the farmers i.e. 53 of them did not follow the SHC recommendations, whereas they had followed their own dosages. Among them, it is seen that a vast majority had applied excess quantity of inputs. On enquiry they reasoned that the recommendations are less reliable, exact application of fertilizer recommendations is difficult, unscientific method of soil sample collection, recommendations not suitable for specific village conditions, expectations of high returns by applying more than recommended doses, and following neighbouring farmers in applying fertilizers.

\section{Constraints Faced in Adoption of SHC Recommendations}

The distribution of respondents according to the constraints faced in adoption of SHC recommendations is presented in Table 7.

Table 7. Distribution of Respondents According to Constraints faced in Adoption of SHC Recommendations

\begin{tabular}{|c|l|c|}
\hline S1.No. & \multicolumn{1}{|c|}{ Constraints } & Per cent (n=100) \\
\hline 1. & Inadequate follow-up by extension agency & 63.00 \\
\hline 2. & No visible results & 43.00 \\
\hline 3. & Complex to adopt the recommendations & 26.00 \\
\hline 4. & Less knowledge & 23.00 \\
\hline 5. & Less benefit & 14.00 \\
\hline 6. & Lack of time & 11.00 \\
\hline 7. & Peers do not follow & 9.00 \\
\hline 8. & Unscientific method of collecting soil samples & 9.00 \\
\hline 9. & High cost & 3.00 \\
\hline
\end{tabular}

It is observed from Table 7 that the foremost constraint expressed by the respondents was inadequate follow-up by extension agency (63.0\%), followed by no visible results (43.0\%), complex to adopt the recommendations (26.0\%), less knowledge $(23.0 \%)$, less benefit $(14.0 \%)$, lack of time $(11.0 \%)$, peers do not follow and unscientific method of collecting soil samples $(9.0 \%)$, and finally higher cost (3.0\%).
Suggestions to enhance adoption level of Soil Health Card (SHC) recommendations

The suggestions elicited from Farmers and Extension functionaries so as to improve the adoption level of SHC recommendations are presented in this section.

\section{Suggestions offered by Farmers}

The distribution of respondents according to the suggestions given by 
farmers for improving the adoption level of SHC recommendations is presented in Table 8.

Table 8. Distribution of Respondents According to Suggestions offered by the Respondents for Enhancing Adoption Level of SHC Recommendations

\begin{tabular}{|c|l|c|}
\hline S1.No. & \multicolumn{1}{|c|}{ Suggestions offered by Respondents } & $\begin{array}{c}\text { Per cent } \\
(\mathrm{n}=100)\end{array}$ \\
\hline 1. & Quick distribution of Soil Health Cards & 96.00 \\
\hline 2. & Follow-up by extension agency & 84.00 \\
\hline 3. & All farmers to be covered under the Bhoochetana project & 71.00 \\
\hline 4. & Conduct of more number of demonstrations & 28.00 \\
\hline 5. & Training on soil sampling and use of SHC & 13.00 \\
\hline 6. & Weekly once visit by AEO to the farmers' fields & 6.00 \\
\hline
\end{tabular}

It is observed from Table 8 that the foremost suggestion expressed by the respondents was quick distribution of Soil Health Cards (96.0\%), followed by follow-up by extension agency (84.0\%), all farmers to be covered under the Bhoochetana project $(71.0 \%)$, conduct of more number of demonstrations (28.0\%), training on soil sampling and use of SHC $(13.0 \%)$, and weekly once visit by AEO to the farmers' fields (6.0\%).

\section{Suggestions offered by Extension Functionaries}

The suggestions offered by Extension Functionaries for increasing adoption level of SHC recommendations are as follows:

- To create more awareness on benefits of SHC based recommendations.
- Inclusion of Soil Health Management in school curriculum.

- Distribution of Mobile soil testing kits.

- To carry out GPS based soil testing.

- Involving other line departments in collection of soil samples.

- Involvement of higher officials of State Department of Agriculture

\section{CONCLUSION}

The Bhootchetana Project is a novel project implemented by the Govt. of Andhra Pradesh in order to encourage farmers to adopt soil test based application of nutrients to soils. It is found through this study that farmers have placed high level of value on SHC based recommendations, which needs 
to be carried forward and capitalized to make the Bhootchetana Project a greater success. On the other hand, itis seen that majority of the respondents had discontinued adoption of SHC recommendations during the course of the five years of implementation of the Project. This issue warrants top most attention and priority by the State Department of Agriculture, considering the time, energy, and money invested in the Bhoochetana project. For this purpose, regular follow-up by the extension machinery is required, so as to prevent discontinuance of adoption of SHC recommendations. In addition, considering the favourable opinion of the farmers on SHC, a separate Monitoring Cell can be thought of- for establishing at the District level. The main functions of the Cell would be to educate farmers on SHM, and encourage them to adopt the
SHC recommendations in a sustained manner.

\section{REFERENCES}

Srivastava, Y.C. \& Pandey, A.P. (1999). Knowledge and Attitude of Small and Marginal Farmers towards Soil Testing. Agricultural Extension Review, 11(6), 3-6.

Theodore, Ravi Kumar. (1988). Awareness, Conviction and Adoption of Technological units of Contingency Farming Practices for Rice by Contact and other Farmers of Thanjavur District, Unpublished M.Sc. (Ag.) Thesis, TNAU, Coimbatore.

Yadav, V.P.S., Raman, .R.S. \& Kumar, R. (2006) Knowledge and Attitude of Farmers towards Soil Testing Practices. Indian Research Journal of Extension Education, Vol. (๑), 3. 